03.1;03.2

\title{
Подавление турбулентности в течениях с вращением
}

\author{
(ㄱ Д.Ю. Жиленко, О.Э. Кривоносова \\ Институт механики Московского государственного университета им. М.В. Ломоносова, \\ Москва, Россия \\ E-mail: jilenko@imec.msu.ru
}

Поступило в Редакцию 20 февраля 2019 г. В окончательной редакции 20 февраля 2019 г. Принято к публикации 23 мая 2019 г.

\begin{abstract}
Экспериментально исследованы возможности управления турбулентностью в сферическом течении Куэтта. Показано, что с увеличением амплитуды модуляции скорости вращения внешней сферы возможно подавление турбулентности с переходом к ламинарному режиму течения. Обратный процесс - восстановление турбулентности - возможен при снижении амплитуды. Установлено, что разрушение турбулентности и ее восстановление сопровождаются гистерезисом. Показано, что при небольших амплитудах модуляции подавление турбулентности возможно только в узкой полосе частот.
\end{abstract}

Ключевые слова: геофизические течения с вращением, подавление турбулентности, сферическое течение Куэтта.

DOI: 10.21883/PJTF.2019.17.48218.17740

Поиску и изучению эффективности методов уменьшения интенсивности турбулентности уделяется в настоящее время большое внимание [1,2]. Подавление турбулентности может происходить при массообмене через границы течения (например, при отборе газа из пограничного слоя [3] или подаче жидкости поперек течения [1]), добавлении частиц твердой фазы в газовый поток [4], воздействии низкочастотных пульсаций [5], импульсном смещении стенки трубы в направлении скорости течения [1], а также другими способами [2]. Подавление турбулентности возможно и в атмосферных процессах, например при ночном охлаждении приземного пограничного слоя атмосферы [6]. Интерес к способам снижения интенсивности турбулентности в течениях с вращением вызван возможностью использования таких способов в технологиях обработки жидких металлов и расплавов, в частности при выращивании монокристаллов из жидких расплавов и растворов [7]. В турбулентных течениях с вращением возможности полного устранения турбулентности показаны численно в случае воздействия осевого магнитного поля на цилиндрическое течение Куэтта [8]. В сферическом течении Куэтта, формирующемся под действием вращения коаксиально расположенных сфер, которое рассматривается в настоящей работе, экспериментально показана возможность снижения интенсивности турбулентных пульсаций азимутальной компоненты скорости [9]. В рассматриваемом случае незначительное (не более 5\%) снижение интенсивности турбулентности происходило под влиянием модуляции скорости вращения внутренней сферы. Тем не менее вопрос о возможности полного устранения турбулентности во вращающихся сферических слоях остается открытым, прояснение этого вопроса и является целью настоящей работы.
Течение в сферическом слое формируется в зазоре между двумя независимо вращающимися прозрачными сферами с радиусами $r_{1}=75 \mathrm{~mm}$ и $r_{2}=150 \mathrm{~mm}$. Зазор между сферами заполнен силиконовым маслом с вязкостью $v \approx 5 \cdot 10^{-5} \mathrm{~m}^{2} / \mathrm{s}$ при температуре $22^{\circ} \mathrm{C}$, в которое для визуализации течения добавлена алюминиевая пудра. С целью стабилизации температуры в слое и сохранения сферичности границ внешняя сфера помещалась в термостат, также заполненный силиконовым маслом. Температура измерялась датчиком, расположенным на экваторе внешней сферы, и поддерживалась постоянной (с точностью не менее $\pm 0.05^{\circ} \mathrm{C}$ ). Измерения азимутальной скорости течения $u_{\varphi}$ проводились лазерным анемометром в точке вблизи внешней сферы, удаленной от плоскости экватора на расстояние $0.078 \mathrm{~m}$ и от оси вращения на $0.105 \mathrm{~m}$. Скорость вращения внутренней сферы $\Omega_{10}$ поддерживалась постоянной. Скорость вращения внешней сферы $\Omega_{2}(t)$ изменялась: $\Omega_{2}(t)=\Omega_{20}(1+A \sin (2 \pi f t+\varphi))$, где $A-$ амплитуда модуляции, $f$ - частота модуляции, средняя погрешность рассматриваемых величин не превышала $0.05 \%$ от заданных значений. Методика проведения экспериментов была следующей. Сначала при встречном вращении границ и отсутствии модуляции $(A=0)$ формировалось исходное турбулентное течение. Особенностью выбранных исходных турбулентных режимов является то, что с уменьшением числа Рейнольдса $\operatorname{Re}_{1}=\Omega_{10} r_{1} / v$ происходит переход к ламинарному, симметричному относительно экватора периодическому режиму течения с тремя вихрями, распространяющимися в азимутальном направлении, и этот переход происходит с гистерезисом [10]. Вблизи порога перехода к турбулентности из ламинарного течения при возрастании чисел Рейнольдса в ней наблюдаются распределенные случайным образом фрагменты пространственных структур, характерные 
Границы области гистерезиса при $f=0.02 \mathrm{~Hz}$ (при повышении $A$ выше $A_{1}$ происходит подавление турбулентности и переход к ламинарному течению; при снижении $A$ ниже $A_{2}$ происходит возврат от ламинарного течения к турбулентности)

\begin{tabular}{c|l|l}
\hline $\begin{array}{c}\text { Амплитуда } \\
\text { модуляции }\end{array}$ & ИТ I & ИТ II \\
\hline$A_{1}$ & 0.1 & 0.0638 \\
$A_{2}$ & 0.046 & 0.059
\end{tabular}

для предшествующего переходу течения [10]. Переходы между периодическим и турбулентным режимами течения легко визуализируются. В качестве исходных турбулентных течений (ИТ) рассматривались два, числа Рейнольдса которых выше соответствующих значений на границе области гистерезиса: $\operatorname{Re}_{2}=\Omega_{20} r_{1} / v=900$, $\operatorname{Re}_{1}=434$ - ИТ I, $\operatorname{Re}_{2}=\Omega_{20} r_{1} / v=700, \operatorname{Re}_{1}=382-$ ИТ II. Оба течения получены путем повышения $\operatorname{Re}_{1}$ при постоянной величине $\mathrm{Re}_{2}$. Кроме того, в качестве исходного рассматривалось турбулентное течение внутри области гистерезиса $\left(\operatorname{Re}_{2}=\Omega_{20} r_{1} / v=700, \operatorname{Re}_{1}=377-\right.$ ИТ III), которое получалось из ИТ ІІ путем уменьшения $\mathrm{Re}_{1}$ при постоянном значении $\mathrm{Re}_{2}$. Визуализация течений при ИТ I и II проводилась при частоте модуляции $f=0.02 \mathrm{~Hz}$, ИТ III - в диапазоне частот модуляции $0.01<f<0.06 \mathrm{~Hz}$. Все измерения при ИТ ІІ и ИТ III проведены при $f=0.02 \mathrm{~Hz}$.

После установления каждого из перечисленных выше исходных турбулентных течений при выбранной величине $f$ амплитуду $A$ увеличивали от нуля до заданного значения (но не более $20 \%$ от $\Omega_{20}$ ). Выяснилось, что увеличение $A$ во всех рассмотренных случаях может приводить к подавлению турбулентности, которая сменяется ламинарным течением. Структура ламинарного течения подобна структуре упомянутого выше периодического течения, которое при стационарных граничных условиях предшествует турбулентности. В спектре ламинарных течений (рис. $1, a$ ) присутствуют пики на частоте модуляции $f=0.02 \mathrm{~Hz}$ и пики на собственной частоте $\left(f_{2}=0.06 \mathrm{~Hz}\right.$ при ИТ II и $f_{3}=0.053 \mathrm{~Hz}$ при ИТ III). Уменьшение А при ИТ І и ИТ ІІ приводит к восстановлению турбулентности. В этом случае при подавлении турбулентности и ее восстановлении наблюдается гистерезис (см. таблицу). При ИТ III с уменьшением $A$ ламинарное течение остается. Спектры турбулентных течений, показанные на рис. $1, b$, соответствуют спектрам двумерной турбулентности, поскольку на меньших частотах можно выделить участок с постоянным углом наклона, близким к величине $-5 / 3$, а на больших частотах - к величине -3 .

На рис. 2 приведены фрагменты зависимости от времени $\Omega_{2}(t)$ и $u_{\varphi}(t): a, b-$ разрушение турбулентности и переход к ламинарному течению после увеличения $A, c-$ восстановление турбулентности после уменьшения $A$. Также на рис. $2, a, b$ приведены

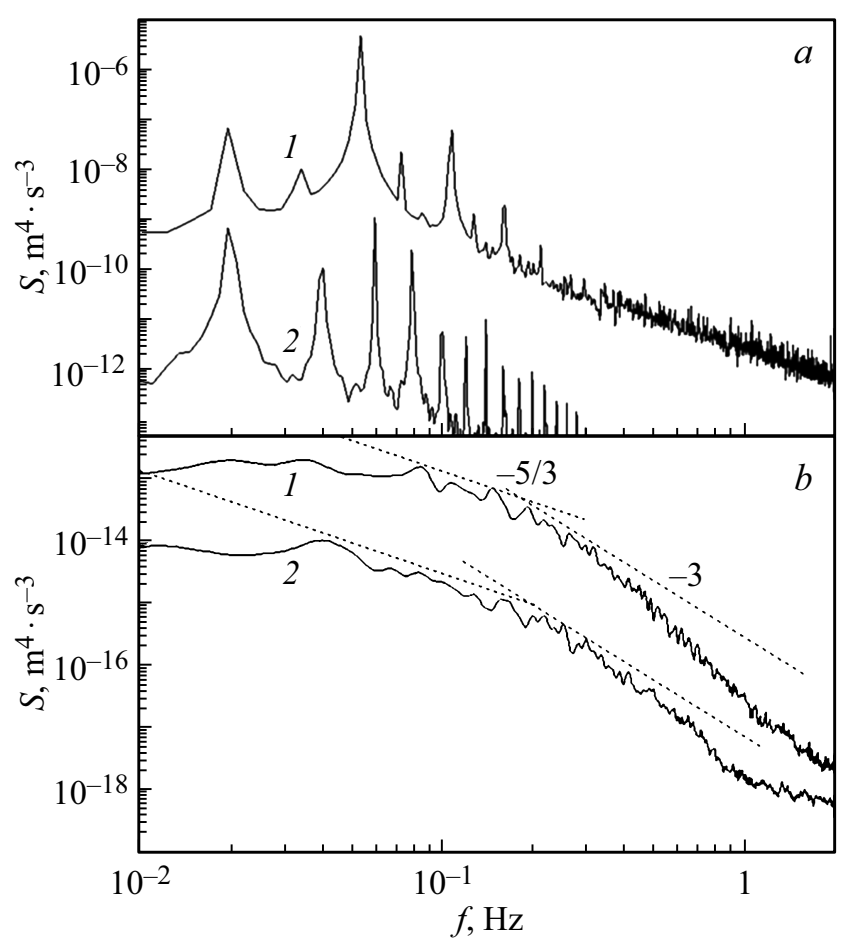

Рис. 1. Спектры $u_{\varphi}^{2}$ ламинарного $(a)$ и турбулентного $(b)$ течений при $f=0.02 \mathrm{~Hz}$. Кривые 1 - ИТ III, $A=0.02$; кривые $2-$ ИТ II, $A=0.15$.

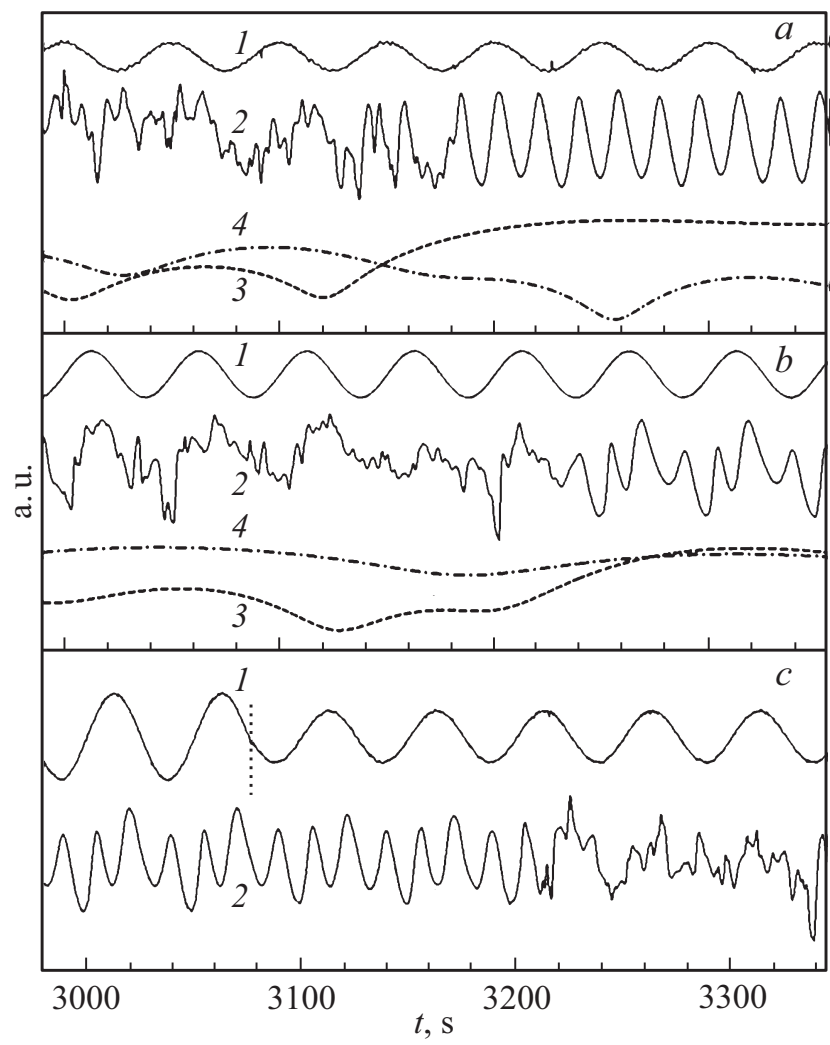

Рис. 2. Зависимость от времени сглаженного сигнала $\Omega_{2}(t)(1), u_{\varphi}(2)$, амплитуды на частоте когерентных структур (3), амплитуды на частоте модуляции $f=0.02 \mathrm{~Hz}$ (4). $a-$ ИТ III, $A=0.02 ; b-$ ИТ II, $A=0.15 ; c-$ ИТ II, переход от $A=0.1$ к $A=0.059$ (момент изменения $A$ показан вертикальной пунктирной линией). 
зависимости от времени амплитуд на частоте модуляции и на собственных частотах ламинарных режимов. Амплитуды $A_{f}(t)$ рассчитаны тем же, что и в [11], методом, основанным на использовании преобразования Гильберта (НT): $A_{f}(t)=\left|u_{f}(t)+i \mathrm{HT}\left(u_{f}(t)\right)\right|$, где $u_{f}(t)$ для каждой из частот определяется исходя из $u_{\varphi}(t)$ с помощью процедуры фильтрации в полосе частот $f \pm \Delta f$, $\Delta f=0.005 \mathrm{~Hz}$. Характерное время роста амплитуды от локального минимума, предшествующего стадии окончательного возрастания, до момента разрушения турбулентности составляет примерно один период колебаний (рис. 2, $a, b)$. При ИТ III модуляция практически не оказывает влияния на форму ламинарной части сигнала (рис. $2, a)$, и в этой части $A_{0.053}(t) \gg A_{0.02}(t)$, где $A_{0.053}(t)$ и $A_{0.02}(t)$ - рассчитанные величины амплитуд на частотах $f=0.053 \mathrm{~Hz}$ и $f=0.02 \mathrm{~Hz}$ соответственно. В случае ИТ II амплитуды близки, и видна сильная амплитудная модуляция ламинарной части сигнала (рис. 2, b).

Интересно отметить, что разрушение турбулентности при возрастании $A$ происходит в момент времени, близкий к минимуму $\Omega_{2}(t)$ (рис. 2, $\left.a, b\right)$. Восстановление турбулентности после уменьшения $A$ происходит при прохождении максимума $\Omega_{2}(t)$ (рис. 2,c). В рассматриваемом диапазоне изменения параметров течения $\left(700<\mathrm{Re}_{2}<900\right)$ чем выше величина $\mathrm{Re}_{2}$, тем выше величины $\operatorname{Re}_{1 c r}$, соответствующие как порогу формирования турбулентности при увеличении $\mathrm{Re}_{1}$, так и порогу ее затухания при снижении $\mathrm{Re}_{1}$. Поэтому уменьшение $\operatorname{Re}_{2}$ при постоянной величине $\operatorname{Re}_{1}$ (а именно это происходит при достижении минимума $\Omega_{2}(t)$ ) соответствует большей надкритичности турбулентности, т.е. большей разнице $\operatorname{Re}_{1}-\mathrm{Re}_{1 c r}$. Ранее в [10] было показано, что при небольшой надкритичности корреляционная размерность возрастает с увеличением $\mathrm{Re}_{1}$. Получается, что подавление турбулентности происходит в той области параметров, которая более удалена от границы формирования турбулентности, где уровень стохастичности при стационарном вращении более интенсивен. И наоборот, восстановление турбулентности наблюдается при попадании в область параметров, близкую к границе формирования турбулентности, где уровень стохастичности при стационарном вращении ниже. По крайней мере первая часть этого результата соответствует имеющимся данным для течения в трубе [1], где одним из возможных способов подавления турбулентности является повышение ее интенсивности на входе в трубу.

Величина амплитуды модуляции $A_{1}$, соответствующая подавлению турбулентности, зависит от частоты модуляции $f$, и эта зависимость существенно нелинейная (рис. 3). В диапазоне изменения $f$ от 0.01 до $0.018 \mathrm{~Hz} A_{1}$ увеличивается по мере роста частоты. Это может объясняться более быстрым пространственным затуханием в радиальном направлении более высоких частот [12]. По-видимому, по этой же причине в связи с имеющимися в эксперименте ограничениями на

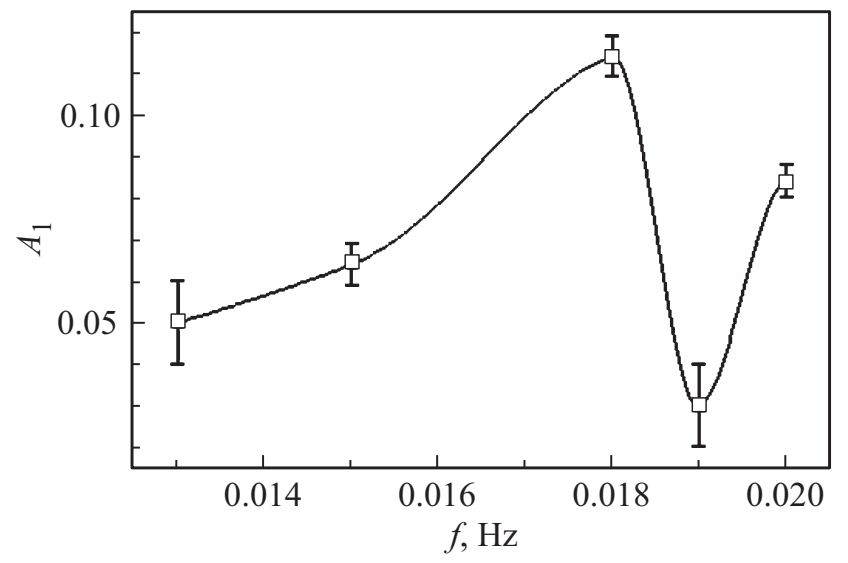

Рис. 3. Зависимость амплитуды модуляции $A_{1}$, соответствующей подавлению турбулентности, от частоты модуляции $f$ для ИТ III. Вертикальные линии соответствуют величине шага ступенчатого изменения $A$, при котором происходило подавление турбулентности.

величину $A$ не удалось добиться разрушения турбулентности при $f>0.02 \mathrm{~Hz}$. В диапазоне изменения $f$ от 0.018 до $0.02 \mathrm{~Hz}$ наблюдается локальный минимум величины $A_{1}$. Частота, соответствующая локальному минимуму, оказывается близкой к 1/3 от собственной частоты ламинарных режимов. Поскольку в ламинарном сигнале три вихря, указанная частота соответствует частоте прохождения одного вихря. Поэтому можно сделать вывод, что турбулентность наиболее восприимчива к возмущениям, частота которых соответствует частоте прохождения одного вихря предшествующего турбулентности периодического течения.

Таким образом, модуляция скорости внешней сферы на частоте, не превышающей частоты прохождения одного вихря в предшествующем турбулентности ламинарном течении, может привести к подавлению турбулентности. Как возрастание амплитуды сигнала на частоте когерентных структур, так и разрушение турбулентности происходят в моменты времени вблизи минимума скорости внешней сферы. Восстановление турбулентности при снижении амплитуды модуляции происходит в моменты времени, близкие к максимуму скорости внешней сферы, и при меньших величинах амплитуд модуляции, чем при ее подавлении.

\section{Финансирование работы}

Работа выполнена при частичной финансовой поддержке Российского фонда фундаментальных исследований (проекты № 18-08-00074 и 19-05-00028).

\section{Конфликт интересов}

Авторы заявляют, что у них нет конфликта интересов. 


\section{Список литературы}

[1] Kühnen J., Song B., Scarselli D., Budanur N.B., Riedl M., Willis A.P., Avila M., Hof B. // Nature Phys. 2018. V. 14. N 4. P. 386-391.

[2] Корнилов В.И. // Теплофизика и аэромеханика. 2005. Т. 12. № 2. C. $183-208$.

[3] Леонтьев А.И., Лущик В.Г., Якубенко А.Е. // ТВТ. 2010. Т. 48. № 3. С. 396-401.

[4] Терехов В.И., Пахомов М.А. // ЖТФ. 2011. Т. 81. В. 10. C. $27-35$.

[5] Бражников М.Ю., Колмаков Г.В., Левченко А.А., МежсовДеглин Л.П. // Письма в ЖЭТФ. 2005. Т. 82. В. 9. С. 642 646.

[6] Donda J.M.M., van Hooijdonk I.G.S., Moene A.F., van Heijst G.J.F., Clercx H.J.H, van de Wiel B.J.H. // Quart. J. Roy. Meteorol. Soc. 2016. V. 142. N 695. P. 781-792.

[7] Нашельский А.Я. Производство полупроводниковых материалов. М.: Металлургия, 1989. 272 с.

[8] Leng X., Kolesnikov Y.B., Krasnov D., Li B. // Phys. Fluids. 2018. V. 30. N 1. P. 015107.

[9] Жиленко Д.Ю., Кривоносова О.Э. // Письма в ЖТФ. 2017. T. 43. В. 10. С. 87-94.

[10] Жиленко Д.Ю., Кривоносова О.Э. // ЖТФ. 2010. Т. 80. В. 4. C. 16-23.

[11] Zhilenko D., Krivonosova O., Gritsevich M., Read P. // Chaos. 2018. V. 28. N 5. P. 053110.

[12] Жиленко Д.Ю., Кривоносова О.Э. // Письма в ЖЭТФ. 2016. T. 104. В. 8. С. 552-559. 